Secondly, of the blunt hook. The shape and size of the instrument are accurately indicated by the annexed figure. Being formed with a view to its turning freely in a small and deep space, its object is to pass beneath the rectus muscle at its narrowest part, in such a manner as to inclose all the fibres of the latter at once, and bring the muscle perfectly into view, without causing it to be violently stretched, or the globe pulled from its socket; a process which causes intense pain to the patient, when a straight or slightly curved director is used to separate the muscle from the sclerotic.

Its advantages to the surgeon are, that he can readily secure the whole muscle, and separate it to any extent he pleases, without using more force than necessary to separate the cellular tissue between the muscle and the globe; also, should any fibres remain undivided, he can, in consequence of the free motion which the peculiar curve of the hook allows, readily find them: it likewise enables him to make an even division of the fibres of the muscle, which, with the scissors (without the use of the director or hook), cannot be done.

To the patient the advantages of this hook over the common director are inestimable, as it saves all the pain caused by the stretching of the nerves, and of the parts which attach the eye to the orbit.

Its advantage over the scissors (when used without the director or hook) is, that it allows of an even division of the muscle close to its insertion; for in many cases where the muscle is not cleanly and closely divided to its insertion, the irregular fibres swell, become inflamed, and granulate, so as to require several applications of caustic or sulphate of copper during two or three weeks after operation.

In no case where I have employed the hook and divided the muscle evenly, and close to its insertion, has the application of any caustic been required.

Lastly, with reference to the knife.-There are still two important questions before the profession as to the mode of dividing the internal rectus muscle for strabismus; namely, Is the knife or the scissors the best instrument to divide the muscle? And is it advisable to employ a straight or slightly-curved grooved director to raise the muscle from the globe for the purpose of facilitating the division of the muscle? The objections to the use of the straight or slightly-curved director are the same under all circumstances; namely, the pain given to the patient during the act of passing the director beneath the muscle, which is always in proportion to the smallness and the depth of the eye, with respect to the brow and cheek, and the difficulty caused to the surgeon by the patient's resistance from the continued pain during the division of the muscle, or search after uncut fibres.

Therefore, it needs only to speak of the scissors and knife, as employed without a director. To the use merely of the scissors, the objections which present themselves are, the bruised wound, the irregular division of the muscle, and the difficulty which often arises of obtaining a sight of the fibres of the muscle after the first incision, for the inner canthus is generally filled with blood; and unless time be taken to sponge the part and stop the bleeding, the remaining steps of the operation must be involved in obscurity, and uncut fibres sought for and divided in the dark. To the use of a knife without a director or hook, the objections are so obvious, that I believe few surgeons have tried the experiment; though I regret to say, I have seen a surgeon of very great experience attempt this, and the consequences were, as might have been expected, a wound in the sclerotica, and the escape of the vitreous humour.

Should the muscle have been secured by means of a hook, and a knife be desired to divide the muscle, two questions suggest themselves; namely, Should the muscle be divided from within to without, or from without to within? And what kind of knife is adapted for the purpose? The blunt-pointed bistoury has been employed to divide the muscle from within to without, between its insertion and the hook ; but the objections to the use of the bistoury are, the difficulty of getting it under the muscle, particularly where the eye is small and sunken; the pain it occasions to the patient during the time it is being pressed forward and through the muscle, after the manner of a sharp wedge (there being seldom room to permit of any sawing motion with the edge of the bistoury, therefore it must, more or less, while being pressed forward through the muscle, raise the eye from its socket); and, lastly, the danger there is of the patient making an accidental resistance while a sharpcutting instrument is fixed between the muscle and the globe. The common scalpel has likewise been employed to divide the muscle between the insertion and the hook, cutting in a direction from without, inwards; the only objections to which are, the difficulty the surgeon experiences in applying the cutting edge of the instrument in a direction favourable to a quick and clean division of the muscle, and the danger, at the same time, of its being thrust into the eye during any sudden resistance of the patient.

To lessen these difficulties and dangers, I beg to suggest to the profession the use of a knife, which has afforded me the utmost facility in effecting a speedy and clean division of the muscle close to its insertion. It possesses all the properties of a scalpel ; namely, utility, effectiveness, and safety, in a smaller space than any other instrument with which I am acquainted, that has been adopted for dividing the internal rectus muscle. The blade consists of two parts; a rounded portion resembling the blunt part of a hernia knife, and a small, sharp, flat extremity, having a transverse cutting edge, which at one end terminates in a shoulder, by uniting with a short, sharp, front edge, while its other extremity forms a point by meeting the back edge at right angles; so that we have the transverse effective part of the blade in immediate connexion with the useful shoulder and point. The annexed engraving is a correct representation of the knife as made by Mr. Weiss.

The instrument described cannot be thrust into the eye by any sudden accidental resistance of the patient; and this safety is owing to the position of its straight-cutting edge, which does not require any sharp part of the knife to be directed towards the globe of the eye during any moment of the operation; the muscle being slightiy raised across the blunt hook, its fibres are divided transiersely by the knife, its edge being directed towards the hook, but at right angles to it, so that the flat side of the blade is held towards the eye.

I am, gentlemen, your obedient serrant,

$$
\begin{aligned}
& \text { 2i, New Broad-street, City, } \\
& \text { Jan. 29, 1841. }
\end{aligned}
$$

\section{ON INQUESTS HELD BEFORE NON-MEDICAL CORONERS.}

\section{(From "The Times" of January 26th.)}

TO THE EDITOR OF THE TIMES.

Sin,-Having read with attention your able remarks on the exertions made by Mr. Wakley, in his capacity of coroner, on some recent occasions of great public interest, I take leave to offer a few observations on the subject of inquests, which observations are the results of extensive practical experience as a medical man.

Inquiries into the cause of death are too frequently conducted in so careless and slovenly a manner as to become a mere matter of form; and verdicts are often returned 
from partial and imperfect evidence, and sometimes without any evidence at all. It is occasionally difficult, and perhaps impossible, to ascertain the cause of death; but this would seldom happen if the investigation were made with the patience and perseverance evinced by Mr. Wakley. Men are often elected to the office of coroner who are so totally unfit for its duties, as to be quite unequal to conduct an inquiry themselves, or direct a jury. Of this $I$ have seen many lamentable instances. In this pari of the country the evidence of a medical man is generally dispensed with, and a post-mortem examination is a matter of very rare occurrence; so that unless the cause of death be obvious and visible, it is scarcely ever ascertained, and the coroner directs the jury to find a verdict of "death by the visitation of God," which they return accordingly. I have witnessed many cases in which different conclusions would have resulted, if the investigation had been conducted by professional men, with ability and patience; but, as coroners are generally without professional experience, and have much on their hands, sufficient time and attention are not always bestowed to elicit all the circumstances connected with the death, and arrive at the truth. I always view the attendance of an attorney on the part of the friends of the deceased, " to watch the proceedings," with jealousy, and believe it to be more calculated to obstruct the truth than to bring the whole of it before the jury. Of this I have seen some examples. That verdicts are sometimes returned directly at variance with the evidence adduced is quite certain; and it is equally clear that the most absurd ones are recorded in cases where the causes of death are obscure, in which the coroner (as is too much the practice) advises the jury that an examination is unnecessary. Before the municipal reform act was passed, the offices of chief magistrate and coroner of this town were united, and during my mayoralty I had many opportunities of observing these facts. Had I at that time known the extent of a coroner's power as well as I now do, my conduct would have been very different. I remember the case of a man who fell from a chair in which he was sitting, whilst drinking at a public-house, and died almost immediately. The medical man stated the cause of death to be " a congestion." I told the jury that it was not a satisfactory explanation, and suggested the propriety of an examination : the jury, however, did not think it requisite; and, upon the foreman inquiring of the surgeon what was likely to have occasioned the congestion, he received for answer, "any pressing emergency, such as falling from a height," when a verdict of " natural death" was immediately returned. On one occasion I was called to a man who had received a violent blow from another with whom he was fighting: he was picked up in a state of insensibility, and died in a few hours. On the inquest I refused to give any evidence without making an examination, and received a reluctant permission. On opening the head a large artery was found to have been ruptured, and a quantity of blood extravasated on the brain. I explained this to the coroner and jury, and, to my utter astonishment, a verdict of " accidental death" was returned.

But the public are chiefly indebted to Mr. Wakley for unfolding the secrets of the prison-house, and rigorously investigating the cause of death amongst the poor in unionhouses, of which that of James Lisney* and others have Jately presented most melancholy examples. Had he been the coroner of this district during that awful period when 40 per cent. of the poor perished in the Bridgewater union, inquest upon inquest would have been held, and his labours would have occupied a year in the inquiry; but those victims were silently passed to their graves-no judicial inquiry of any kind was instituted. It is true that a mock inquiry into this wholesale desolation was instituted under the auspices of Assistant-commissioner Weale (who had successively tried love, law, and preaching, but who found this new occupation more profitable than either of his former ones,) before the board of guardians and himself,

- Hendon Union. who were deeply implicated in the charge of neglect, and who, as a matter of course, acquitted themselves of all blame. All the ingenuity, however, of this man of allwork, could not prevent an inquiry before a select committee of the House of Lords, before which this and many other appalling facts were established by a host of witnesses, as a reference to the evidence taken before that committee will fully prove. Much praise, too, is due to Mr. Wakley for the protection which his late examinations into the cases of malapraxis in labour and childbed affords to the poor, which must necessarily lead to the detection of instances of gross ignorance and inattention, and cannot fail of producing salutary effects. 'That women often die during labour from want of proper assistance is certain, and my own observation convinces me that such deaths have been much more frequent since the poor have been under the operation of that hard-hearted law, commonly called "The Poor-law Amendment Act," have either been refused their accustomed aid, or consigned to the care of adventurers and incompetent and unqualified practitioners. I could fill the columns of the Times if I detailed the many fatal cases which have come within my knowledge, but I cannot forbear mentioning the following two: one was that of a poor, but most industrious and respectable, woman, whose former labours had been such as to require the assistance of one and sometimes two surgeons, who was refused by the board of guardians, to whom her husband applied, the assistance of the parish surgeon, and died in consequence, leaving five children. This poor woman had on a former occasion been attended by the parish surgeon, assisted by another surgeon, in consequence of the difficulty and danger to be apprehended; the child died, and the mother was only saved by great exertion. On the approach of her next confinement, her husband, a labourer of excellent character, working for $8 s$. a week, lost a day's work to come in himself to the board of guardians of the Bridgewater union, and petition for the assistance of the union surgeon. His own account is as follows :"I went to the board at Bridgewater on a Friday, the chairman was there, and asked me what I wanted. I said, a note for my wife to have the doctor when she was put to bed, for that she had a very bad time before, and had two doctors with her. He told me to go out and wait, and the gentlemen would consult. I was kept there waiting an hour and a half, when the relieving-officer came out and told me that no note was granted. When I got home and told my wife that the doctor was not to be allowed, she was very much cast down." The poor woman was taken in labour that day fortnight, without any assistance but an ignorant midwife, until it was too late, and she died from the consequence of excessive hæmorrhage! The other was a case in which the necessary aid was so long delayed, that she also died, leaving eleven children. I saw both these cases myself; and, after an extensive experience of forty years, am warranted in saying, that both these women would have been saved, if timely assistance had been afforded. An inquest ought to have been held in each of these cases, and a most rigid examination of all the attendant circumstances instituted; but, perhaps, if this had been done under the direction of an incompetent coroner, the same result would have been obtained as in the case of a professional gentleman of my acquaintance, who insisted on inquiry under similar circumstances; for which offence he was reprimanded by the board of guardians, and threatened to be dismissed. The verdict in that case was, that the woman "died from neglect;" but the jury forbore to specify on whom the neglect ought to have been charged.

In all such cases $I$ should regard the presence of an assistant commissioner, or any of the functionaries connected with the administration of the poor-law, with great suspicion. Their object appears to be to throw every obstacle in the way of fair and impartial inquiry; and no one who has read with attention the late proceedings in the case of the Eton union, and the extraordinary report of Assistant-commissioner Parker, can deny the fact, These 
officials intrude themselves into courts of inquiry, for the purpose of bolstering up a system which the good sense and humanity of Euglishmen must either pat a stop to, or so entirely alter as to deprive it of all its harsh and cruel enactments. Every week, nay, almost every day, produces some new example of New Poor-law horrors, and of impertinence on the part of its functionaries. On the 18 th of December last, James West, an old man of 83, was found dead in his bed in the Bridgewater union-house. It appeared in evidence that his supper was taken up to him the night before, which was the last time he was seen alive; and, as no satisfactory account could be given of his death, the coroner advised the jury that the proper verdict should be "found dead." The clcrk of the union (who had been called to answer some question about the bed-clothes, which were supposed to have been too scanty,) instantly started up, and most impertinently told the coroner that he had no right to direct the jury, and that he did not know his duty; upon which the coroner ordered him to be silent, but he still persisted, until a threat of committal put a stop to his indecent interference. Whilst the jury were viewing the body another old man fell out of his bed, into which he was replaced by some of the jury. He died on the following day, but no inquest was held on him.

Such facts show but too strongly the important duties to be performed by coroners, and the obligations which the public are under to those who discreetly and fearlessly perform the high duties of their office, particularly in the innumerable cases of death under the New Poor-law, where every effort is made to shield abuses and obstruct the course of justice. I am, sir, your humble servant,

Bridgewater, Jan. 15, $1841 . \quad$ Jonathan Toogood.

\section{PROVINCIAL MEDICAL AND SURGICAI, ASSOCIATION.}

\section{EXPLANATORY OBSERVATIONS BY THE POOR-LAW} COMMTTEE.

Severar medical gentlemen, equally anxious with ourselves that the question of parochial relicf should be equitably and satisfactorily adjusted by parliament, have signified to us that it is highly undesirable, and might even prove fatal to our common object, were the power of regulating the mode and fixing the amount of remuneration to union medical officers entrusted absolutely to the poor-law commissioners, as proposed by Mr. Serjeant 'Talfourd's third clause.

Although the clause which has been objected to, would have the effect of compelling the commissioners to carry their own recommendations (founded upon medical evidence) into effect, and although we fully appreciate the various difficulties attendant upon any attempt to define the remuneration,-preferring a judicious system of administration to minute and complex legislation,-yet, in deference to the opinions of others, and deeply convinced of the importance of endeavouring to settle this longdebated question, we have prepared a serics of clauses, providing for the alleged defect in our measure, and based on the principle unanimously recommended by Dr. Kay and the medical witnesses in 1838: but we propose to allow a discretionary power to the authorities of determining the remuneration wit? in certain fixed limits.

We believe that these limits will be found to coincide with the estimate of payment and general features of the plans proposed by the British Medical Association to the poor-law commissioners, in 1839, and to Lord John Russell, in 1840; although we beg to observe that the average rate suggested by that association could not form part of a legislative enactment, because any fiture arerage must necessarily be doubtful, and depend on the results of the operation of different rates previuusly fixed according to particular circumstances.
Our first duty was, therefore, to define the mode of preparing a list of the paupers in every parish who should be entitled to medical relief without the necessity of any specific order; and if, in doing this, we adopt a somewhat different method from that recommended by the poor-law commissioners in their last report, it is because we are fully convinced that the latter would be found inconvenient, if not impracticable, and certainly at variance with some of their own propositions. Instead, therefore, of confining the preparation of this list to the commencement of every year, and excluding all persons, however similarly circumstanced, who might fairly be placed on that list at subsequent periods of the year, we provide for a weekly revision and amendment of the list; at the same time we would carefully preclude the guardians of the poor from adding to this list any sick or injured persons requiring immediate relief.

The average of the weekly numbers on the list, taken at the end of the year, appears to be the proper fixed number by which to compute the medical remuneration.

We also find it necessary to propose a separate list for each parish, instead of for each district, as proposed by the poor-law commissioners; and for this reason,--that the difference in the distance from medical advice, between the various parishes belonging to the same district, would cause a uniform rate of remuneration (which we presume must be applied to all persons on the same list) to press inequitably and disproportionately on the populous home parishes. The poor-law commissioners have elsewhere discovered this very inconvenience (see Appendix, Last Report, p. 98, Warrington Union), and it would be still more generally perceived under the operation of our seventh printed clause, which involves a principle of such vital importance that it could not be omitted unless separate parochial charges were fully provided for in the remuneration clause.

Next, as to the amount of payment. It seems to be generally admitted that, exclusive of the items of distance and area (that is to say, in cities and towns), the sum of $5 s$. per case would provide adequately for medical relief. We, therefore, propose a minimum $4 s$. $6 d$. and a maximum $6 s$., to permit those variations which the different circumstances and customs of towns in various parts of the kingdom might indicate.

Then, in order to apply this rate to the pauper list, we estimate the proportion of " cases" to "paupers" at 67 per cent., or as two to three; a ratio deduced from several authentic statistical calculations, and judiciously adopted by the British Medical Association. It follows, therefore, that the sum per head for the pauper list should be twothirds of the payment per case ; we would, accordingly, fix the minimum and maximum at $3 s$. and $4 s$. But if these rates (in schedule $A$ and $B$ ) be considered too low, it might be desirable to fix $5 s$. as the minimum remuneration per case, and $3 s .4 d$. as the minimum for the pauper list. On this point we would be guided by the opinions of our professional brethren. Then we consider that the additional rate for journeys in rural districts should, with regard to cases not on the pauper list, deperid on the distance of each individual case from the medical officer; but with respect to the pauper list, that it should depend on the distance and area of the parish.

The area would, of course, form an essential item of cost in parishes containing a resident medical officer; and it is also a necessary consideration in distant large parishes, at least if the distance be measured (as we believe it must be) to the nearest part of the parish.

We are of opinion that the charge for distance should bear an exact and constant proportion to the rate of remuneration as fixed within the specified limits, and we have assumed that one-fourth part additional for each mile would meet the increased trouble and expense of the medical oflicer. If, however, any other proportion be generally considered desirable, we are ready to assent to it; but it should be such a proportion as admits of easy calculation.

We will illistrate the operation of this clause in the case 